\title{
Prasasti Huludayeuh
}

\section{Hasan Djafar}

Keywords: inscription, Ancient Sunda, Hindu-Buddha, Sri Baduga Maharaja

\section{How to Cite:}

Djafar, H. Prasasti Huludayeuh. Berkala Arkeologi, 14(2), 197-202. https://doi.org/10.30883/jba.v14i2.723

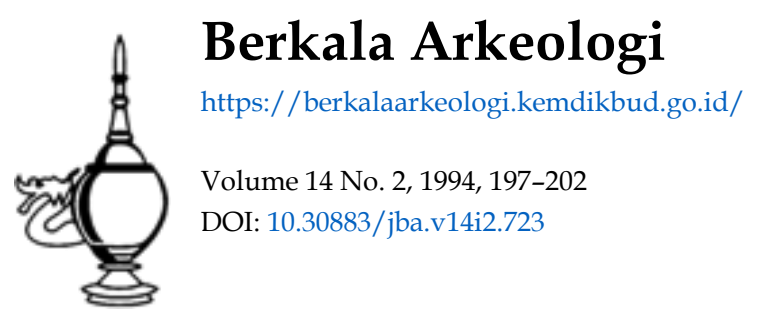

\section{cc) (i) (2) (2)}

This work is licensed under a Creative Commons Attribution-NonCommercial-ShareAlike 4.0 International License. 


\title{
PRASASTI HULUDAYEUH
}

\author{
Hasan Djafar \\ (Jurusan Arkeologi FS-UI)
}

\section{Pendahuluan}

\subsection{Prasasti-prasasti Jawa Barat}

Salah satu peninggalan arkeologi yang tergolong dalam artefak bertulis ialah prasasti (prasás(i), yaitu penulisan yang dipahatkan pada batu logam, kayu, atau benda-benda lain yang dibuat dari bahan-bahan tersebut. Berdasarkan bahan prasasti dari masa Jawa Kuna terdapat tiga jenis prasasti yang dipakai, yaitu prasasti batu (upala prasảsti), prasasti tembaga (tamra prasāstı), dan prasasti pada lontar (ripta prasāstı)

Pada umumnya prasasti merupakan dokumen resmi yang dikeluarkan oleh raja atau pejabat kerajaan. Sebagian besar prasasti berisi keputusan atau maklumat tentang penetapan suatu daerah atau sebidang tanah menjadi perdikan (sima), kadang-kadang berupa tanda peringatan mengenai suatu peristiwa. Akan tetapi tidak jarang pula terdapat prasasti yang berisi pertulisan yang amat pendek, kadang-kadang hanya berupa sebuah kata atau nama, dan angka tahun saja.

Sebagai sumber sejarah dan kebudayaan prasasti mempunyai kedudukan yang amat penting, karena merupakan sumber keterangan yang sejaman. Keterangan-keterangan yang tersimpan dalam sebuah prasasti apabila diteliti dengan seksama dapat memberikan gambaran mengenai beberapa aspek kehidupan masa lampau, seperti struktur kerajaan, birokrasi, kemasyarakatan, perekonomian, agama, dan adat istiadat dalam masyarakat (Boechari, 1965:48; 1972:2, 22)

Tidak jarang pula terdapat prasasti yang memberikan sumbangan yang penting dalam penelitian mengenai perkembangan bahasa dan pertulisan. Prasasti tertua di Jawa Barat, bahkan di seluruh Pulau Jawa, ditulis dengan huruf Palawa dan bahasa Sanskrta. Prasasti ini berasal dari masa pemerintahan Pūrnawarman raja Tārumānagara, dari pertengahan abad ke-5. Prasastiprasasti lainnya ditulis dengan huruf Jawa Kuna dan Sunda Kuna, dan menggunakan bahasa Jawa Kuna, Malayu Kuna, dan Sunda Kuna.

Peninggalan prasasti di Jawa Barat ditemukan tersebar di beberapa tempat, namun sampai kini jumlahnya masih sedikit jika dibandingkan dengan temuan di daerah Jawa Tengah atau Jawo Timur. Di Jawa Barat hingga kini baru ditemukan 32 buah prasasti yang berasal dari masa Hindu-Budda, terdiri dari 7 buah berasal dari Tärumānagara, dan yang lainnya berasal dari masa kerajaan Sunda (Hasan Dj., 1991; 1992) Sebagian besar prasasti tersebut dipahatkan pada batu, di- goreskan pada lempengan tembaga, dipahatkan pada arca batu, dan sebuah lagi tertera pada kentongan (kohkol) perunggu

Penelitian terhadap prasasti dan penggunaannya sebagai sumber sejarah kuna, khususnya sejarah Jawa Barat, telah lama dilakukan. Namun hampir semua prasastı tersebut hingga kin masih mempunyai banyak permasalahan yang belum terselesaikan. Salah satu permasalahan yang amat penting dan mendasar ialah masalah pembacaannya. Kekeliruan atau ketidaktepatan dalam pembacaan dapat menimbulkan perbeda. an penerjemahannya, dan dapat menimbulkan kekeliruan yang lebih jauh lagi dalam pemahaman dan penafsiran isi prasasti tersebut dalam merekonstruksikan kesejarahannya. Beberapa kendala yang ada, seperti kondisi prasasti --terutama prasasti batu-- yang sudah sangat usang dan aus, serta ada bagian-bagian prasasti yang patah atau hilang tidak memungkinkan lagı untuk memberikan pembacaan yang lengkap dan akurat. Bahkan tidak jarang pula di antara prasasti yang telah ditemukan itu sekarang sudah tidak diketahui lagi keberadaannya, sehingga tıdak memungkinkan untuk mengadakan pembacaan langsung dari prasastinya Dengan demikian tidaklah mengherankan apabila terdapat transliterasi hasil pembacaan sebuah prasasti tersaj। tidak lengkap atau masih bersifat sementara

Kendala lain dalam menghadapi sumbersumber berupa prasasti ini ialah yang berkaitan dengan kemampuan kita tentang penguasaan pengetahuan bahasa dan pertulisan kuna. Pengetahuan kita tentang bahasa-bahasa kuna kadang masih belum cukup memadai untuk dapat menerjemahkan dan memahami ISI sebuah prasasti. Masih banyak sekali Istilah dan kosa kata dalam prasasti yang belum dapat kita ketahuı dan fahamı artı atau padannya dalam bahasa kita sekarang

Dengan keadaan sepertı Inı dan ditambah masih sedikitnya sumber-sumber lain yang dapat dipergunakan sebagal bahan pelengkap atau pembanding, sejarah kuna Jawa Barat masih sangat fragmentaris dan memiliki bagıan-bagıan yang belum dapat diketahui dengan past।

Dengan demikian setiap ada penınggalan arkeologi, baik yang berupa peninggalan bertulıs maupun peninggalan tak bertulis yang baru ditemukan, dapat saja memberi tambahan data. Data tersebut dapat memperjelas permasalahan dan dapat melengkapı gambaran tentang aspek 
aspek kehidupan masyarakat pada masa lampau yang telah ada. Demikian pula halnya dengan temuan baru berupa sebuah prasasti batu dari daerah Cirebon

\subsection{Riwayat penemuan dan deskripsı prasastı}

Prasasti yang menjadi obyek penelitian ini adalah sebuah prasasti batu yang kini terdapat di tengah sawah di blok Huludayeuh, Desa Cikalahang, Kec. Sumber, Kab. Cirebon, Jawa Barat. Berdasarkan nama tempat penemuannya prasasti ini kami namai prasasti Huludayeuh.

Walaupun prasasti ini telah lama diketahui penduduk setempat, namun kalangan ahli arkeologı dan sejarah baru mengetahuinya dalam Bulan September 1991, melalui pemberitaan surat kabar harian Pikiran Rakyat dan Kompas.

Keadaan prasasti Huludayeuh sekarang sudah tidak utuh lagi. Beberapa bagian batu prasasti inı di bagian kiri dan kanannya sudah patah dan hilang, sehingga beberapa kata dan hurufhuruf prasastinya turut hilang pula. Keadaan prasastinya sudah aus, terutama di bagian atas, sehingga sebagian tulisannya sudah tidak jelas lag!. Batu prasasti tersebut berukuran tinggi $75 \mathrm{~cm}$, lebar 35 acm, dan tebalnya sekitar $20 \mathrm{~cm}$ tidak merata. Tulisannya yang masih tampak terdiri dari 11 baris. Akan tetapi mungkin sekali ketika ması utuh prasasti ini terdiri lebih dari 11 baris tulisan. Ditulis dengan huruf Jawa Kuna dan berbahasa Sunda Kuna." Tulisannya dipahatkan tegak dan rapih, dengan be-sar huruf sekitar 1,5 sampai $3 \mathrm{~cm}$. Bentuk huruf pada prasasti Kuburajo dari Raja Adityawarman, ${ }^{4}$ dan prasasti Batutulis Bogor

\section{Transkripsi}

Pembacaan prasastı Huludayeuh yang dilakukan secara lengsung ketika diadakan penelitıan di lapangan telah menghasilkan transkripsi sementara. Transkripsi inı telah disiarkan dalam makalah yang disampaikan pada Seminar Nasio. nal Sastra dan Sejarah Pakuan Pajajaran di Bogor, pada tanggal 11-13 November 1991 (Hasan

\footnotetext{
Penamaan prasasti biasanya dilakukan berdasarkan topomik, yaitu penamaan mengikuti nama tempat yang disebutkan di dalam prasasti (Damais, 1952; 1970). Karena prasasti ini tidak menyebutkan nama tempat, maka penamaantyo didasarkan pada nama tempat penemuarma, yaitu Huludayeuh.

Lihat harian Pikran Ramat 11 September 1991, dan harian Kompas, tanggal 12 September 1991.

Ketika berita penemuan prasasti ini disiarkan di harian Pikran Raktat dan Komoas pada Bulan September 1991, prasast ini disebutkan ditulis dalam huruf Palawa dan dihubungkan dengan Raja Pumawarman dari Tarumanagara.

H. Kem. Versoreide Geschiften, VII, 1917:218.
}

Djafar, 1991:29) Transkripsi sementara prasastı tersebut masih belum memuaskan dan masih dapat disempurnakan lagi. Hal itu terutama disebabkan karena beberapa bagian dari prasastinya telah hilang disamping banyak pula terdapat huruf-huruf yang sudah aus dan tidak jelas lagı. Dengan demikian prasasti tersebut sangat sulit dibaca di tempat secara langsung dalam waktu yang relatif singkat. Transkripsi hasil pembacaan sementara tersebut kemu-dian kami lengkapi dengan hasil pembacaan berulang-ulang melaluı foto dan acuan kertas (abklatsch) yang telah kami buat di lapangan

Berikut ini adalah hasil dari pembacaan ulang prasasti tersebut.

1. ... (ra)tu purana ${ }^{4}$

2. ... sri mah haraja 3 ra(tu)

3. (ha)jif ri pakwan/ sya san ra(tu)

4. (de)wata 5 pun/. masa sya

5. ... Brétakón/ bumi zaha

6. ... lipukŏn/ na bwan/na

7. ... ñariah sañ dw_ı sisuk laja

8. ... . ja orbahkŏn/ikar. ka

9. ... susipadakan zalasan/

10. ... na 'udubasu mipatā

11. .. 0is/ nikari kala

\section{Catatan Iranskriosi}

1. Huruf ra pada kata ratu tidak begitu jelas karena bagian depannya terpotong. Tanda suku (-u) pada suku kata tu dipahatkan terlalu panjang dan melengkung ke kiri sehingga menyerupai cakra (-ra). Di bagian pangkalnya pahatannya lebih tebal dan lebih dalam, sehingga timbul kesan mungkin sekali tanda cakra itu merupakan kesalahan citralekha untuk menuliskan tanda suku, yang kemudian diperbaik! dengan cara mempertebal bagian pangkainya agar dapat dibaca sebagal -u. Bandingkan bentuk penulisan tanda baca $-u$ ins dengan yang terdapat pada kata-kata bumi (baris ke5), sinusuk/(baris ke-7) dan iudubasu (baris ke-10)

2. Tanda suku pada suku kata pu- dipahatkan terlalu kecil, dan ditempatkan di tengah-tengah bagian bawah huruf.

3. Kata maharaja dalam prasasti ini dituliskan menjadi mah harala, menggunakan dua buah tanda $/ \mathrm{h} /$, yaitu sebuah visarga $(\Sigma)$ dan sebuah huruf $\cup$.. Penggunaan sebuah vi. sarga di tengah sebuah kata memang tidak lazım, namun dalam prasasti Sunda yang laın yaitu dari daerah Lampung Selatan, kita dapatkan gejala pemakaian hal tersebut Pada prasasti Kebantenan IV, barıs ke-3 (recto) terdapat kata-kata: paluiurah han/ dan pallmahhan/ (Hasan, 1991:12) Di dalam prasasti Ulubelu (D.145) pada baris ke-4 terbaca kata 
brahma, 일... (Damals, 1962:290, pl bovi)

4. Huruf la dengan tanda cécak (-i) cukup jelas terbaca walaupun terpotong pada bagian depannya.

5. Huruf wa masih jelas terbaca walaupun bagian depannya terpotong sedikit.

6 Tanda cěcak $(-1)$ masih jelas terlihat walaupun huruf yang terletak di bawahnya sudah tidak terbaca lagi karena sudah patah dan aus.

\section{Tinjauan Isi Prasasti}

Dari transkripsi prasasti Huludayeuh yang tersaji di muka sangat sulit untuk dapat menerjemahkan dan mengetahui isi keseluruhan prasasti tersebut. Namun dari penggalan-penggalan kalimat dan kosa kata yang tersisa masih dapat kita ketahu beberapa bagian isi-nya dan hal-hal lain yang terdapat dalam prasasti tersebut.

Kita masih beruntung, dalam prasasti Huludayeuh ını masih dapat dibaca potongan-potongan nama raja yang disebutkan di dalamnya. dari baris pertama sampai baris keempat terbaca dengan cukup jelas ... tu purana ... sri mahharaja ra ... ii ri pakwan / sya san ra ... wata pun!.

Berdasarkan perbandingan dengan nama raja yang disebutkan di dalam prasasti-prasastı Sunda yang lain, yaitu yang disebutkan di dalam prasasti Kebantenan I (E.42a), prasasti Kebantenan II (E.43), prasasti Kebantenan IV (E.45), dan prasasti Batutulis, serta nask ah Sunda Carita $\mathrm{Pa}$ rahiyanan, dapatlah kita mengetahui nama raja terseb8t secara lengkap. ${ }^{5}$ Raja yang disebutkan daiam prasasti Huludayeuh tersebut tidak lain ıalah Ratu Purana Srı Baduga Sri Mahārāia Ratu Hall Ii Pakwan Sya San Ratu Dewata, yaitu seorang raja Sunda yang memerintah pada tahun 1481-1521 (Saleh, Danasasmita, dkk., 1983:III, hlm 53, IV, him 3, 36)

Pada baris ke-3 prasastı Huludayeuh terdapat kata tunjuk lokatif ri (=di) di depan nama tempat Pakwan. Pada prasasti-prasasti Sunda yang lain kata tunjuk lokatif ini selalu ditulis di (lihat: Tabel 1). Pemakaian kata tunjuk lokatif II pada prasasti Huludayeuh yang berbahasa Sunda Kuna Inı memperlihatkan adanya pengaruh pemakalan bahasa Jawa Kuna.

Prasasti ini dikeluarkan sebagai tanda peringatan atas usaha-usaha kebajikan yang telah dilakukan oleh Sri Baduga Maharaja. Hal ini dapat diketahui berdasarkan keterangan yang tercantum dalam baris ke-4 dan seterusnya. Barisbaris tersebut antara lain mengemukakan: "

masa sya … nrětakön / bumi gaha … lipukön '

Lihat variasi penyebutan nama-nama raja tersebut pada lampiran I. dan transkripsi prasasti-prasasti pada lampiran II-V. na bwan / na ... " (" ... ketika beliau ... menye jahterakan bumi, mengha ... lipukŏnn di dunia ...").

Pada baris terakhir prasasti in terbaca kata- kata "nikan் kala ... ", dan setelah kata-kata tersebut batu prasasatinya pecah. Mungkin sekal di belakang nikań kala itu tertulis angka tahun atau pertanggalannya. Walaupun angka tahun prasasti ini (seandainya memang ada sepert! yang kami duga) telah hilang, secara relatif dapat diketahui berdasarkan perbandingan dengan prasasti Batutulis dan prasasti Kebantenan. Berdasarkan perbandingan ini prasasti Huludayeuh dapat diperkirakan sejaman dengan prasasti-prasasti tersebut, yaitu dari kurun waktu sekitar awal abad ke-16.

Mengingat prasasti Huludayeuh in! isınya berkenaan dengan usaha memperingati jasa-jasa kebajikan Sri Baduga Maharaja, mungkin sekali prasasti ini tidak dikeluarkan oleh Sri Baduga Maharaja sendiri, melainkan oleh raja penggantinya yaitu Raja Surawisesa (1521-1535). Raja Surawi. sesa pulalah yang mengeluarkan prasasti Batutulis, Bogor, pada tahun Saka pañca-pandawané (m)banbumi", 1455 (= 1533 Masehi), dalam rantóka memperingati jasa-jasa Sri Baduga Maharaja. Di dalam prasasti Batutulis disebutkan jasa-jasa Sri Baduga Maharaja, yaitu: membuat parit pertahanan ibukota Pakuan (nu ñusukna pakwan), membuat monumen Gugunungan (nu ñiyan sa. kakala qugununan), membuat jalan yang diperkeras (n,abalay), membuat hutan cagar (ñiyan samida) dan membuat Sań Hiyañ Talagaréna Mahawijaya.

\section{KEPUSTAKAAN}

Atja.,1968,Tjarita Parahiyangan: Titilar Karuhun Urang Sunda Bandung: Jajasan Kebudajaan Nusalarang

Boechari, 1965, Epigraphy and Indonesian Historiography, dalam:Soedjatmoko et.al (eds.) An introduction to Indonesian Historiography. Ithaca, New York: Cornell University Press, hlm. 47-73

Boechari, 1977, Epigrafı dan Sejarah Indonesıa Majalah Arkeologi, 1(2):1-40

Damais. L.C., 1952, Études Soumaranarses II L'inscription de Ulu Balu (Soumatra Mér.dional), BEFEO, L(2):289- 310.

\footnotetext{
${ }_{5}^{5}$ Lihat prasasti Baturulis. baris $5-8$
} 
Damais, L.C.,1960, Répertorre Onomastique de l'Éprgraphie Javanaise (Jusqu'a Pu Sindok Sri Tsānawikrama Dharmmotungadewa). Études d"Épigraphie Indonésienne PEFEO LXVI.

Hasan Djafar, 1991. Prasasti-prasasti dari Masa Kerajaan-kerajaan Sunda Seminar Nasional Sastra dan Sejarah Pakuan Pajajaran Universitas Pakuan, Bogor, 11-13 Nov.

1992. Prasasti-prasasti Jawa Barat dan Beberiapa Permasalahannya, Gotrasawala Sejarah III: Peninggalan Kepurbakalaan di Jawa Barat. Universitas Pasundan, Bandung, 25 Februari
Kern, H., 1917, Het Sanskrit-inschrift op den grafsteen van Vorst Ádityawarman te Kubur Raja (Měnangkabau: \pm 1300 Ç), Verspreide Geschriften, VII : 215-221

Kompas, (Bandung), 12 September 1991

Pikiran Rakyat, (Bandung), 11 September 1991

Saleh Danasasmita, dkk., 1983, Rintisan Penelusuran Masa Silam: Sejarah Jawa Barat, Jilid III dan IV. Bandung: Pemerintah Propinsi Daerah Tingkat I Jawa Barat.

\section{LAMPIRAN I}

TABEL VARIASI PENYEBUTAN NAMA RANA

\begin{tabular}{|c|c|}
\hline Sumber vang dipakai & Nama raja vang disebutkan \\
\hline $\begin{array}{l}\text { Prasasti Kebantenan I (Jayagiri I), E 42a, } \\
\text { recto: } 3-4\end{array}$ & susuhunan / ayðna di paku ªn / pajajaran \\
\hline $\begin{array}{l}\text { Prasasti Kebantenan \| (Sundasembawa I). } \\
\text { E. } 43 \text { recto: } 1-2\end{array}$ & $\begin{array}{l}\text { sri baduga maharaja ratu haji di pakwan / sri } \\
\text { san ratu dewata }\end{array}$ \\
\hline $\begin{array}{l}\text { Prasastı Kebantenan IV (Gunung Samaya), } \\
\text { E 45, recto: } 1-2\end{array}$ & $\begin{array}{l}\text { sri baduga maharaja ratu haji di pakwan / sri } \\
\text { san ratu dewata }\end{array}$ \\
\hline Prasasti Batutulis (1455 ל̧), barıs: 1-4 & $\begin{array}{l}\text { prěbu ratu purane ... prěbu guru dewata prana } \\
\text { sri baduga maharaja ratu haji di pakwan / } \\
\text { pajajaran / sri sañ ratu dewata }\end{array}$ \\
\hline Carita Parahıyanzan & $\begin{array}{l}\text { sri baduga maharajadiraja ratu haji di pakwan / } \\
\text { pajajaran / sañ hyañ sri ratu dewata }\end{array}$ \\
\hline Prasastı Huludayeuh & $\begin{array}{l}\text { (ra)tu purana (sri baduga) sri mahhharaja ra(tu } \\
\text { ha)ji ri pakwan / sya sañ ra(tu de)wats }\end{array}$ \\
\hline
\end{tabular}

\section{LAMPIRAN II}

\section{PRASASTI KEBANTENAN I (JAYAGIRI I)}

Lempeng E.42a recto:

(1) $/ / 0 /{ }^{\circ}{ }^{\circ} \dot{n}^{\circ}$ awignam $=a s / t u$. nihan/ sakala ra

(2) hyañ nıskala was/tu kañ/cana pun. turun/ka ra

(3) hyań niñrat/ kañ/cana maka nuni ka susuhunan/ 'ayö

(4) na di pakuªn/ pajajaran/ pun/. mulah mo mihape

Lempeng E.421 verso:

(1) dayŏhan/ di jayagiri. dŏn [ baca: jŏn ] dayŏhan/ di su(n/)da sěmbawa.

(2) 'aya ma nu nabayu ${ }^{\circ} a n /$ iña ${ }^{\circ} u l a h ̣$ dek/ nahŏryanan/

(3) 'iña ku na dasa. calagara. kapas/ timban. pare

(4) doñdań pun/. mangaditudi ka para muhara. mulạ̣ dek/ men/

\section{Lempeng E.42b recto.}

(1) ta`an/ iña beya pun/. kena iña nu purab dibuhaya

(2) mibuhayakŏn/na kacarita`an/ pun/. nu pagöh gawaka

(3) $n / n a$ dewa sasan/na pun/ 0.0 


\section{LAMPIRAN III \\ PRASASTI KEBANTENAN \| (SUNDA SEMBAWA $\|$}

Lempeng E.43 recto:

(1) /lo/l pun/. 'ini pitěkět sri baduga maharaja ratu haji

(2) di pakwan/. sri sań ratu dewata. nu dipetěkětan/ mana / baca: nana / lě

(3) mah dewa sasana. su(n/)da sěmbawa. mulaḷ waya nu nubahya

(4) mulah waya nu nahöryanan/ te [ baca: ti ] beh timur/ hañgat/ cira ${ }^{\circ} u b /$

(5) . ka sañ hyañ salila. ti barat/ hañgat/ rusěb/. ka mu(ñ/)jul ka ci

(6) bakeken. ciho(ñ/)je. ka muhara cimu (ñ/)can pun/ . ti kidul/

Lempeng $E .43$ verso:

(1) hańgat/ lowón comon/. mulah mo mihapeya kena

(2) na. dewa sasana sañgar kami ratu. saparah jalan/ gèdé

(3) kagirañkön/. Jěmaḥ laranan/ pigŏsanön/na para wiku

(4) pun/. ulaḥ dek/ waya nu kŏdŏ di bŏnañngin nagurat/ ke

(5) na ${ }^{\circ} a^{\circ}$ iri heman/. di wiku pun/

\section{LAMPIRAN IV \\ PRASASTI KEBANTENAN IV IGUNUNG SAMAYAI}

Lempeng E.45 recto:

(1) //o/l pun/ ${ }^{\circ}$ ini pitékět/ sri baduga maharaja ratu haji di pakwan/ ari sań ratu

(2) dewata. nu dipitěkétan/mana [ baca: nana ] ! maḥ dewa sasana. di gunuñ samaya sugan/n=aya

(3) nu dek/ gahöriyanan/ iña. ku palulurahhan/ pa!lmaḥhan/ mulaḥ `aya

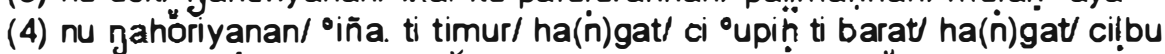

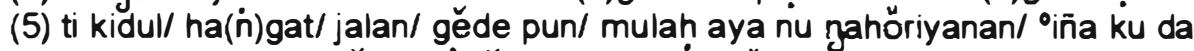

(6) sa ku calagara ${ }^{\circ}$ upéti pañgèrs !̣ma ( baça: rŏma ${ }^{\circ}{ }^{\circ} u l a h ~^{\circ}$ aya nu me(n)ta ${ }^{\circ} a n /{ }^{\circ}$ iña

(7) kena sañgar kami ratu nu puraḥ mibuhayakŏn/na ka ratu pun/ nu pagŏh jawakan

(8) na dewa sasana oun/ o o

\section{LAMPIRAN V \\ PRASASTI BATUTILIS}

(1) wañ na pun/ oiti sakala prěbu ratu purane pun/. diwas/tu

(2) diya winaran/ [ baca: dinaran/] prébu guru dewata prana diwas/tu diya dinaran/ srı

(3) baduga maharaja ratu haji di pakwan/ diya `anak/rahiyan dewa nis/

(4) wata pun/ ya ñusuk/na pakwan/ diya `anak/ rahiyañ dewa nis/

(5) kala sa(in) sida mok/ta di guna tiga. incu rahiyan nis/kala was/tu

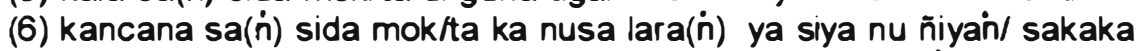

(7) la. gugunan/ nabalay/. ñiyan/ samida. ñiyan/ sa(i்) hiyañ talaga

(8) `ma mahawijaya ya siya. pun/ : 9 \% saka. pañcapan/da

(9) wa jĕ(m)ban/ bumi 


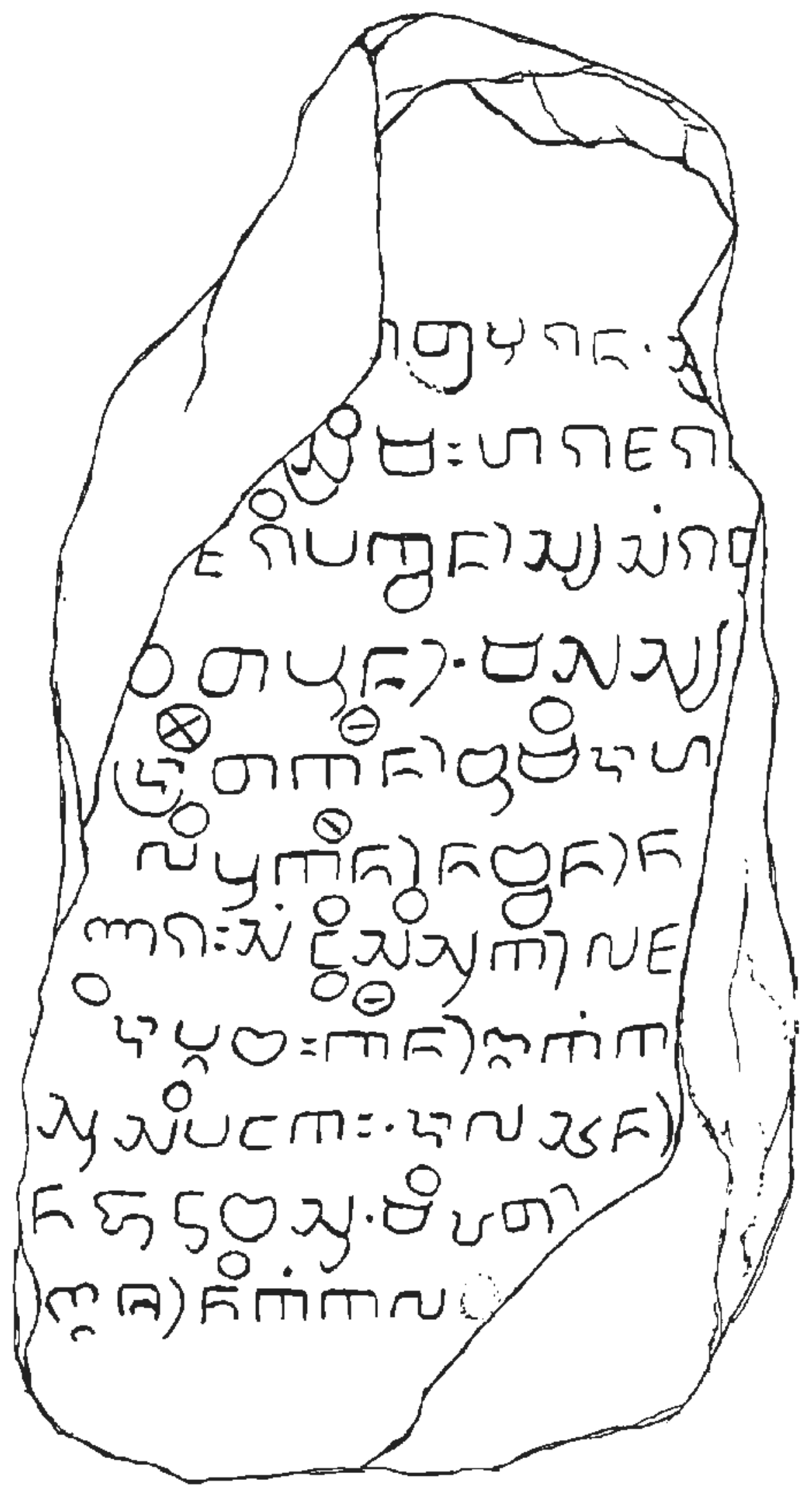

FAKSIMIL PRASASTI HULUDAYEUH 